\title{
mtDNA variation and human-mediated introgression of indigenous Sus populations on several Indonesian islands
}

\author{
Naotaka Ishiguro ${ }^{1, *}$, Yasuo Inoshima ${ }^{1}$, Motoki Sasaki ${ }^{2}$, Akira Matsui ${ }^{3}$, Hitomi Hongo ${ }^{4}$, \\ Ryouhei Takahashi $^{4}$, Wahono Esthi Prasetyaningtyas ${ }^{5}$, Ita Djuwita ${ }^{5}$, Srihadi Agungpriyono ${ }^{5}$, \\ Supratikno5 $^{5}$ Kusdiantoro ${ }^{5}$, Elhayat Labiro ${ }^{6}$, Teguh Budipitojo ${ }^{7}$, Woro Danur Wendo ${ }^{7}$, \\ Dewi Kania Musana ${ }^{7}$ and Takdir Saili ${ }^{8}$
}

${ }^{1}$ Laboratory of Food and Environmental Hygiene, Veterinary Medicine, Faculty of Applied and Biological Sciences, Gifu University, Gifu 501-1193, Japan

${ }^{2}$ Laboratory of Anatomy, Obihiro University of Agriculture and Veterinary Medicine, Obihiro, Hokkaido 080-5111, Japan

${ }^{3}$ Nara National Culture Properties Research Institute, Nara 630-8577, Japan

${ }^{4}$ Department of Advanced Sciences, Graduate University for Advanced Studies, Hayama, Kanagawa 240-0193, Japan

${ }^{5}$ Department of Anatomy, Faculty of Veterinary Medicine, Bogor Agricultural University, Bogor 16680, Indonesia

${ }^{6}$ Department of Biology, Tadulako University, Palu, Sulawesi 94221, Indonesia

${ }^{7}$ Department of Anatomy, Faculty of Veterinary Medicine, Gadjah Mada University, Yogyakarta 55281, Indonesia

${ }^{8}$ Laboratory of Animal Science, Faculty of Agriculture, Haluoleo University, Kendari 93232, Indonesia

\begin{abstract}
To examine the genetic origin of the domestic pig, the distribution of wild boar, and human-mediated translocation of the domestic pig, we collected 223 samples from domestic pigs and wild boars from eight Indonesian islands, sequenced the control region of mitochondrial DNA (mtDNA) from each sample, and compared these sequences with previously determined sequences from East and Southeast Asian domestic pigs and wild boars. Three Sus species (S. scrofa, S. verrucosus, and $S$. celebensis) were identified on the Indonesian islands. The mtDNA sequences of three Indonesian Sus species were diverse, and they clustered into three lineages with low bootstrap values (an S. scrofa group including East and Southeast Asian domestic pigs and wild boars, a group including indigenous $S$. scrofa together with $S$. verrucosus from Sumatra and Java Islands, and an $S$. celebensis group from Sulawesi Island). The mtDNA haplotypes of S. scrofa wild boars from three (Sumbawa, Flores and New Guinea) islands and domestic pigs from two (Lombok and Timor) islands east of the Wallace Line, and some S. scrofa wild boars from Sumatra and Java Islands were related to Vietnamese pig mtDNA sequences in the East and Southeast Asian domestic pig and wild boar clade, supporting that ancient immigrants likely introduced domestic pigs from the Asian continent to east Indonesian islands. The mtDNA haplotypes of $S$. celebensis were broadly divided into three groups, which were distributed in the north and southwest areas, central area and southeast area of Sulawesi Island.
\end{abstract}

Key words: domestic pig, Indonesia, mtDNA, origin, wild boar.

The origin of domestic pigs has been debated for many years. The genus Sus includes ten species: Sus ahoenobarbus, S. barbatus, S. bucculentus, S. cebifrons, S. celebensis, S. oliveri, S. philippensis, S. salvanius, S. scrofa, and S. verrucosus (Grubb 2005; Chen et al. 2007). Sus scrofa is the most widely distributed of these ten species, inhabiting Asia, Europe and northwestern Africa. The other nine Sus species inhabit in limited continental areas or archipelagos, such as the Indonesian islands or Philippine islands. In Indonesia, S. barbatus is endemic to Borneo Island, $S$. celebensis to Sulawesi Island, S. verrucosus to Java Island, and S. scrofa to Sumatra and Java Islands. Giuffra et al. (2000) proposed that the domestic pig was domesticated independently in Europe and Asia from two distinct ancestral populations of $S$. scrofa wild boar and at multiple sites. Mitochon-

*To whom correspondence should be addressed. E-mail: Ishiguna@gifu-u.ac.jp 


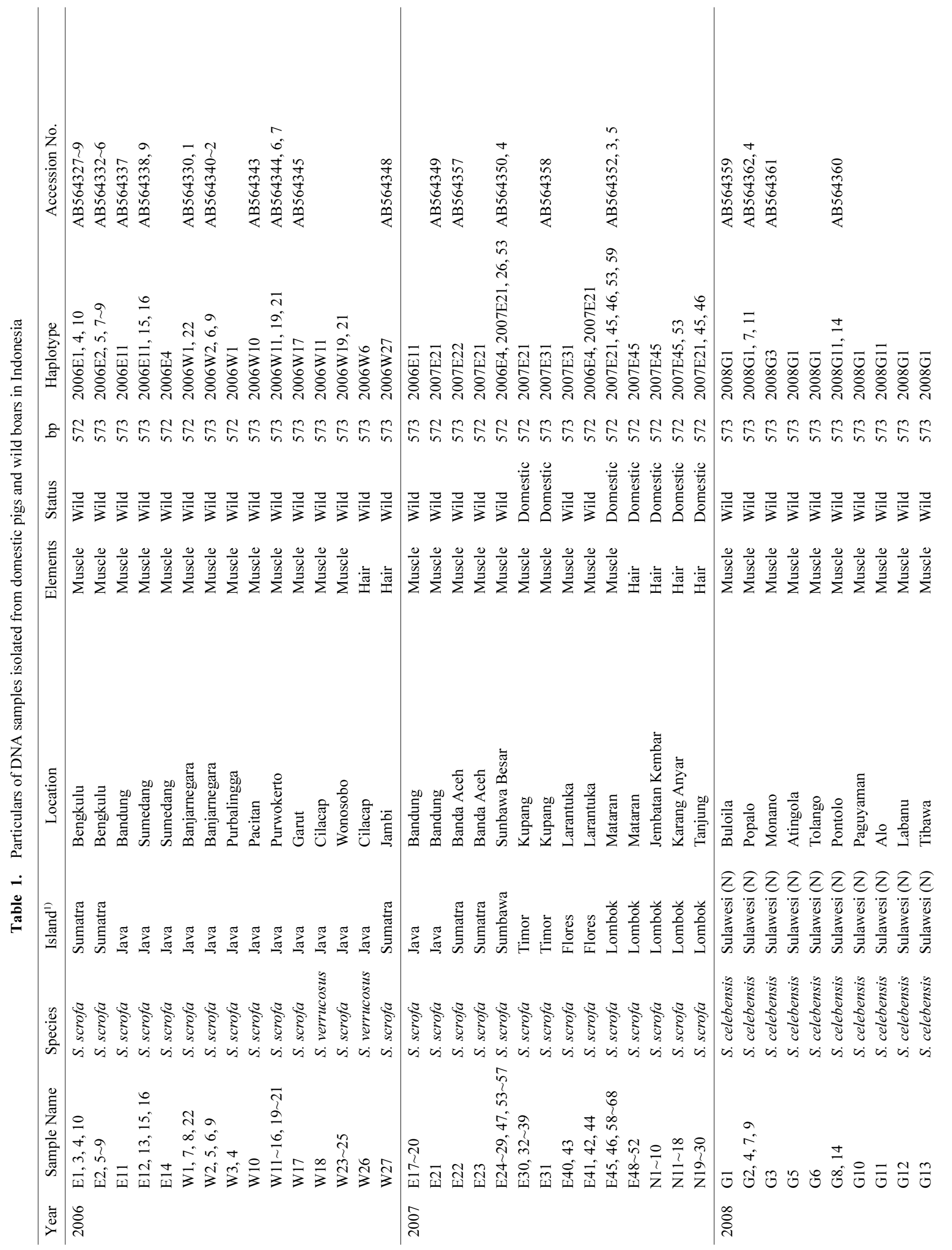




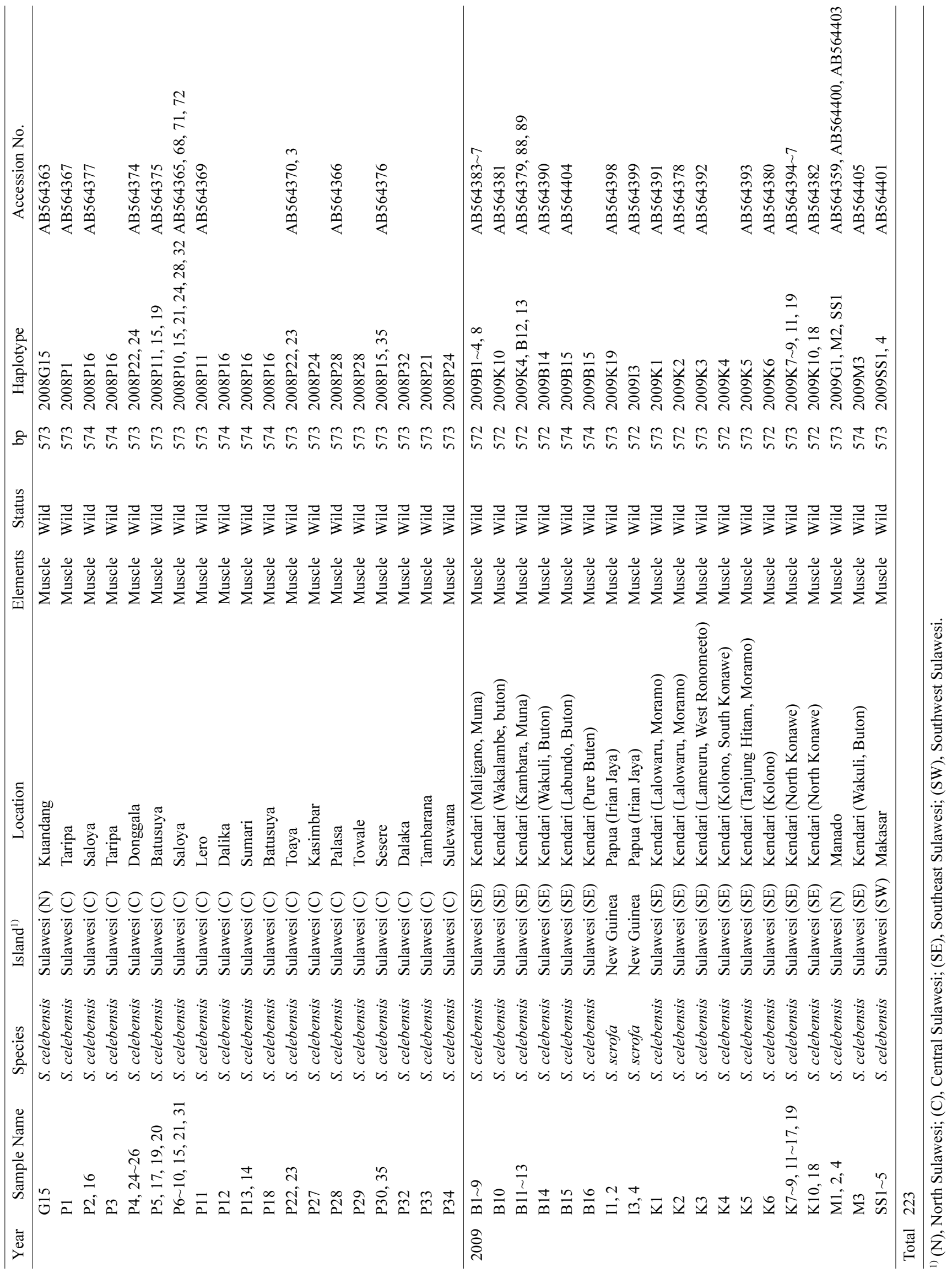


drial DNA (mtDNA) analyses provided compelling evidence for independent domestication events in Europe and Asia from S. scrofa wild boars (Watanabe et al. 1985; Giuffra et al. 2000). Larson et al. (2005) systematically collected modern and ancient DNA samples derived primarily from wild-caught specimens from museum collections, examined mtDNA lineages phylogenetically and revealed that pig domestication from wild boars took place at several sites. Recently, Larson et al. (2010) reported that there are five potential independent domestication sites of indigenous S. scrofa wild boars: one in India; three in peninsular Southeast Asia (including northern Vietnam); and one off the coast of Taiwan. These results indicate that the Southeast Asia peninsula is the main domestication site for Asian domestic pigs.

Independently from Larson's studies (Larson et al. $2005,2007,2010$ ), we analyzed mtDNA samples of $S$. scrofa from Japan and neighboring countries, as well as Vietnam, from 2003 to 2005 in order to explore the genetic origin of domestic pigs (Hongo et al. 2002; Ishiguro et al. 2008a, b). We also visited several Indonesian islands to collect samples over a 4-year period for the present study. The sequences of mtDNA control regions determined from DNA samples of Indonesian domestic pigs and wild boars were compared with previ- ously determined sequences from East and Southeast Asian domestic pigs and wild boars.

In this study, we examined the mtDNA diversity of domestic pigs and wild boars in Indonesia to trace the genetic origin of the domestic pig. The phylogenetic analysis using the data set suggested that the $S$. scrofa from Indonesian islands have high mtDNA diversity, and that indigenous wild boars with unique haplotypes inhabited each island. Some mtDNA haplotypes from S. scrofa wild boar samples from Sumbawa, Flores and New Guinea Islands, the islands east of the Wallace Line, and from $S$. scrofa wild boar samples from Sumatra and Java Islands were closely related to Vietnamese pig mtDNA lineages.

\section{Materials and methods}

\section{Samples}

Tissue samples (223 total: 37 hair samples from domestic pigs and 186 muscle samples from wild boars) were collected from domestic pigs and wild boars in Indonesia from 2006 to 2009 (43 samples in 2006, 82 samples in 2007, 50 samples in 2008, and 48 samples in 2009). Detailed information (island, type of tissue samples, and wild or domestic) for the 223 samples is shown in Table 1. Sample collection sites are shown in Fig. 1.

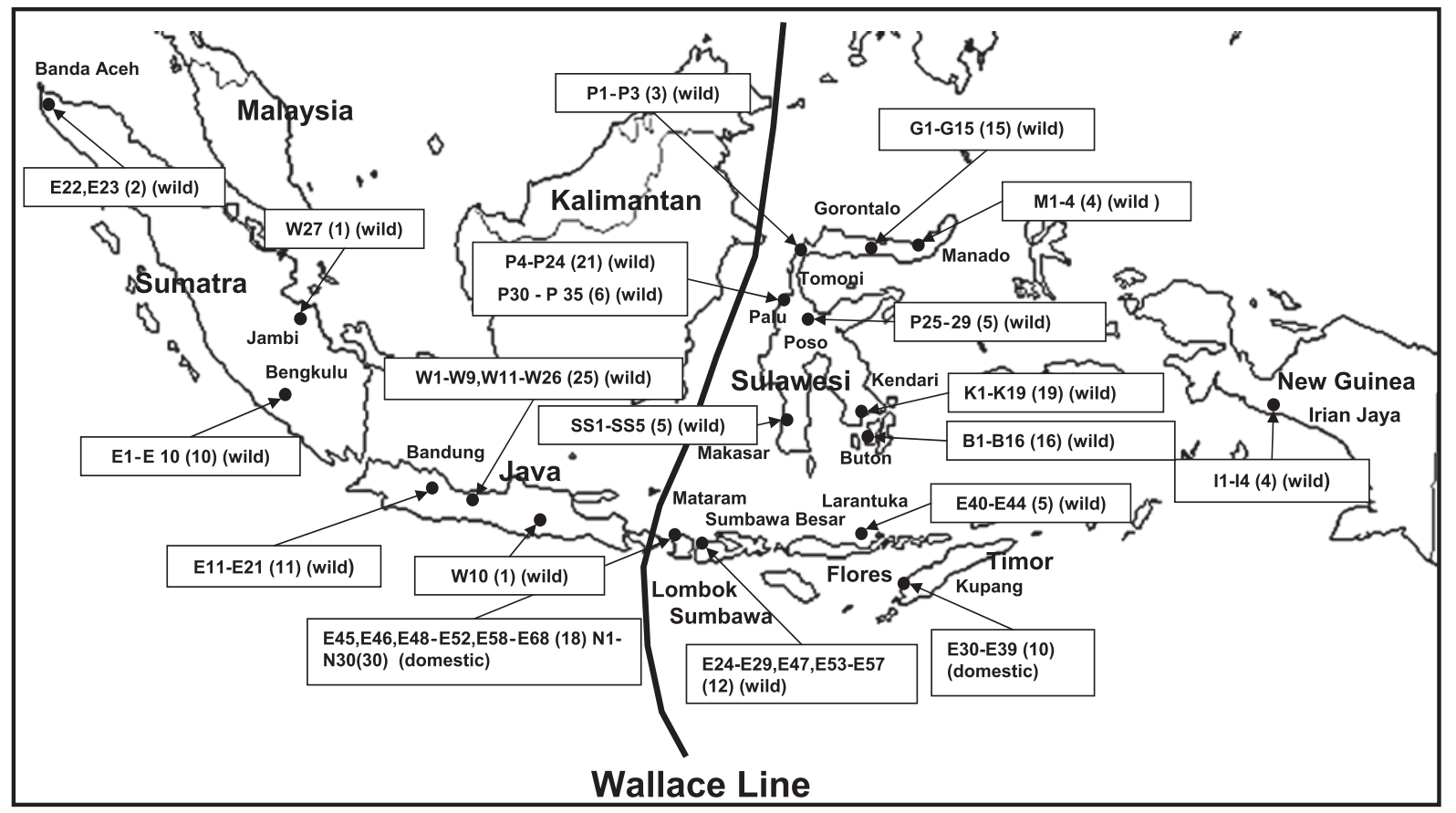

Fig. 1. Sampling sites in Indonesia. Numbers in parentheses indicate the number of samples collected from each site. The Wallace line indicates a geographical division between Australian and Southeast Asian fauna. wild, wild boar; domestic, domestic pig. 
Muscle samples from wild boars on each island were obtained from native hunters. Identification of Sus species for each sample was conducted based on morphological information (e.g., body size) provided by native hunters.

\section{DNA extraction and mtDNA analysis}

Total DNA was extracted from the 37 hair samples and 186 muscle samples using the DNeasy Tissue kit (Qiagen) according to the manufacturer's instructions. The mtDNA D-loop region (572 to $574 \mathrm{bp}$ ) was amplified using two primers, mit112 and mit106 (Watanobe et al. 2003). PCR products were purified using a QIAquick PCR Purification kit (Qiagen), as described by Ishiguro and Nishimura (2005). Sequence reaction of the purified PCR products was then performed using two primers (mit11 and mit12) and a BigDye Terminator v3.1 Cycle Sequencing kit (Applied Biosystems), followed by automated sequencing on an ABI 310 Genetic Analyzer. Novel control region sequences from this study were deposited in GenBank with Accession Nos. AB564327 to AB564405.

\section{Alignment of DNA sequences and phylogenetic analysis} mtDNA sequences (572 to $574 \mathrm{bp}$ ) were aligned with haplotypes published previously (Hongo et al. 2002; Watanobe et al. 2003; Ishiguro and Nishimura 2005; Ishiguro et al. 2008a) using Clustal W (gap opening penalty 15 , gap extension penalty 6.66 ) (Thompson et al. 1994). Genetic distance was estimated by the proportion (P)-distance method in the MEGA4 (Tamura et al. 2007). The corresponding regional sequence of Phacochoerus aethiopicus (Cape and Somali Warthog, AB046876, Okumura et al. 2001) was used as an outgroup. Phylogenetic trees were constructed using the neighbor joining (NJ) method (Saitou and Nei 1987) and the maximum parsimony (MP) method in MEGA4. The confidence of each branch in the phylogeny was estimated using 1,000 bootstrap replications (Felsenstein 1985).

\section{Results}

Nucleotide sequence diversity and phylogenetic relationships

All wild boars sampled from Sumatra, Java, Sumbawa, Flores and New Guinea Islands were identified as $S$. scrofa, except for two $S$. verrucosus individuals from Java Island. All wild boar samples from Sulawesi Island were identified as $S$. celebensis (Table 1).

We detected 77 different mtDNA haplotypes in the 223 Indonesian DNA samples. When the 77 mtDNA haplotypes were compared with previously reported mtDNA sequences, the haplotype of sample No. 2007E45, isolated from Lombok Island, was identical to the haplotype M33 from domestic pig (Ishiguro and Nishimura 2005).

In order to investigate the phylogenetic relationship among the mtDNA haplotypes in the Indonesian Sus samples, an $\mathrm{NJ}$ tree was constructed by using pairwise distance matrix calculated by P-distance with the 77 mtDNA haplotypes identified in this study and $81 \mathrm{~S}$. scrofa haplotypes reported previously (Fig. 2). A nearly identical phylogenetic tree was obtained using the MP method (data not shown). Two haplotypes, 2007E45 (M33) and 2007E46, from domestic pigs on Lombok Island fell into the East and Southeast Asian domestic pig and wild boar clade. Nine haplotypes (2006E1 and 2006E10 from Sumatra Island, 2006E4 from Sumatra and Flores Islands, 2007E21 from Java, Sumbawa, Flores, Timor and Lombok Islands, 2007E26 from Sumbawa Island, 2007E31 from Timor and Flores Islands, 2007E53 and 2007E59 from Lombok Island, and 200913 from New Guinea Island) were related to Vietnamese haplotypes (viet31 and viet12). Among the nine mtDNA haplotypes, seven mtDNA haplotypes (2006E1， 2006E4， 2006E10， 2007E21， 2007E26, 2007E31 and 2009I3) were isolated from S. scrofa wild boars, while four mtDNA haplotypes (2007E21, 2007E31, 2007E53 and 2007E59) were isolated from domestic pigs (Table 1). Some mtDNA haplotypes of wild $S$. scrofa samples from Java and Sumatra Islands clustered with the indigenous wild boar groups in each island (Fig. 2). The mtDNA sequences (2006W6 and 2006W11) of $S$. verrucosus isolated from Java Island were difficult to distinguish from those of $S$. scrofa.

The mtDNA haplotypes of $S$. celebensis from Sulawesi Island formed a unique lineage that differed from the $S$. scrofa lineages in the NJ tree (Fig. 2), although the support value was extremely low (20\%). The nucleotide variation observed in $45 \mathrm{mtDNA}$ haplotypes from Sulawesi Island is shown in Table 2. The mtDNA haplotypes of $S$. celebensis were divided into three genetic groups, A, B, and C, with low bootstrap values (Table 2 and Fig. 2). The geographical distribution of mtDNA haplotypes of $S$. celebensis was plotted on a map of the Sulawesi Islands in Fig. 3. The haplotypes in group A were found from northern and south- 


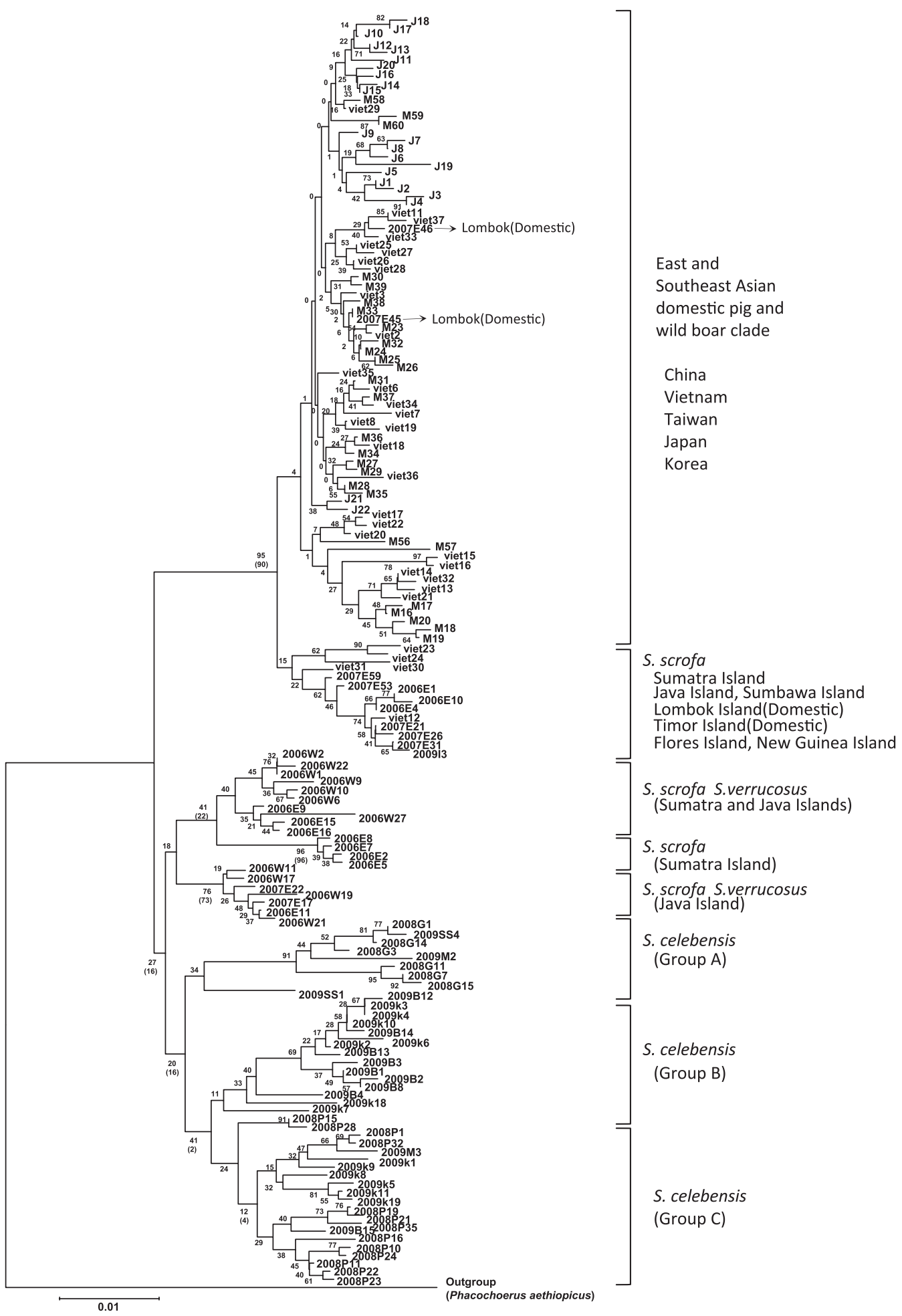

Fig. 2. Neighbor-joining (NJ) phylogenetic tree constructed using the 572-bp to 574-bp mtDNA control region. This tree includes 76 novel mtDNA haplotypes from Indonesia identified in this study and 81 previously reported haplotypes (Hongo et al. 2002; Ishiguro and Nishimura 2005; Ishiguro et al. 2008a). Indonesian mtDNA haplotypes are the same as listed in Table 1. Abbreviations of 81 mtDNA haplotypes J, viet and $\mathrm{M}$ indicate isolation place or origin of $S$. scrofa from Japan, Vietnam, and modern domestic pigs and wild boars from East and Southeast Asia, respectively. Bootstrap resampling was performed 1,000 times. Bootstrap probabilities are shown on corresponding branches. Numbers in parentheses indicate the bootstrap probabilities obtained by the MP method. Indonesian mtDNA haplotypes are indicated by species, sample collection site, and island. 


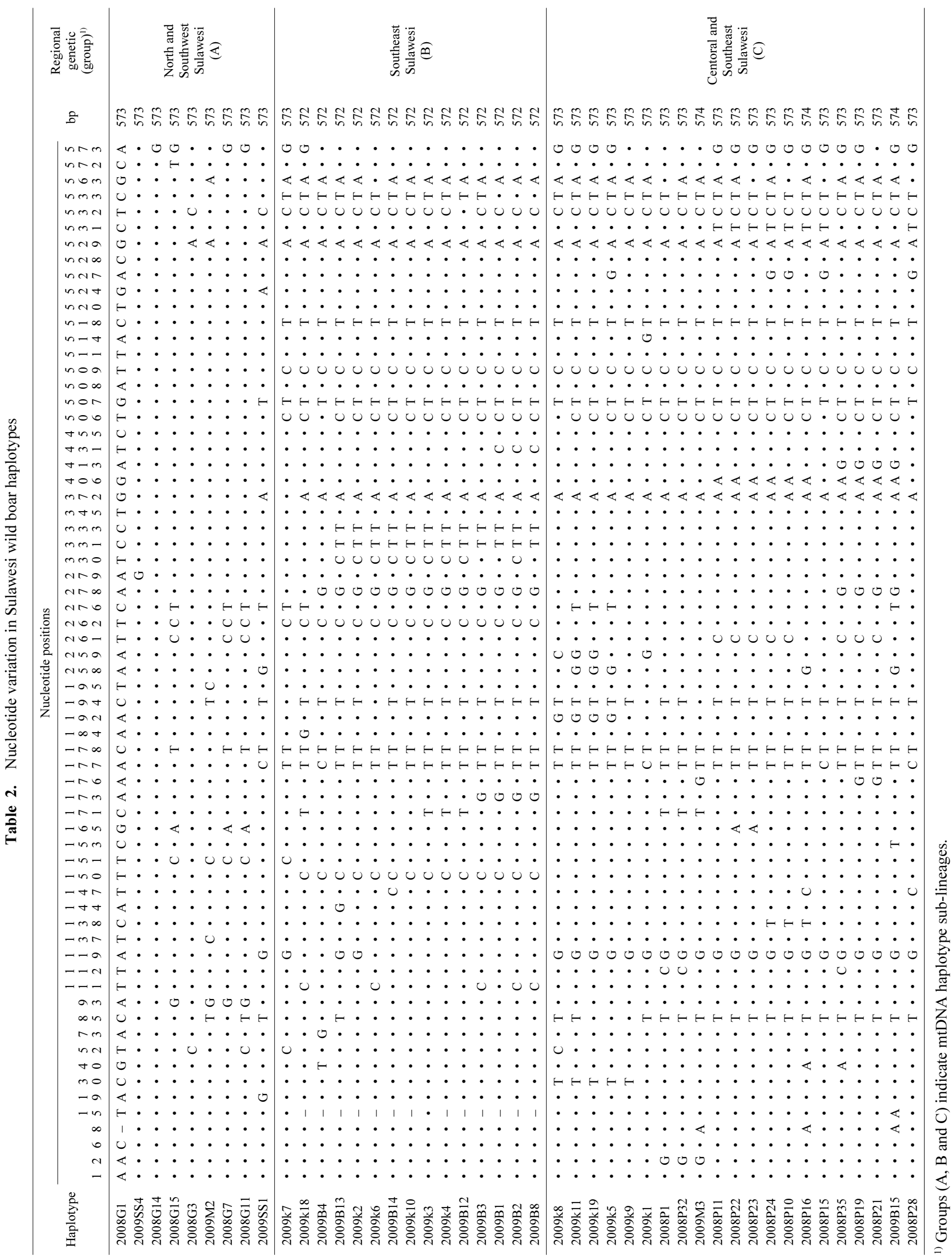




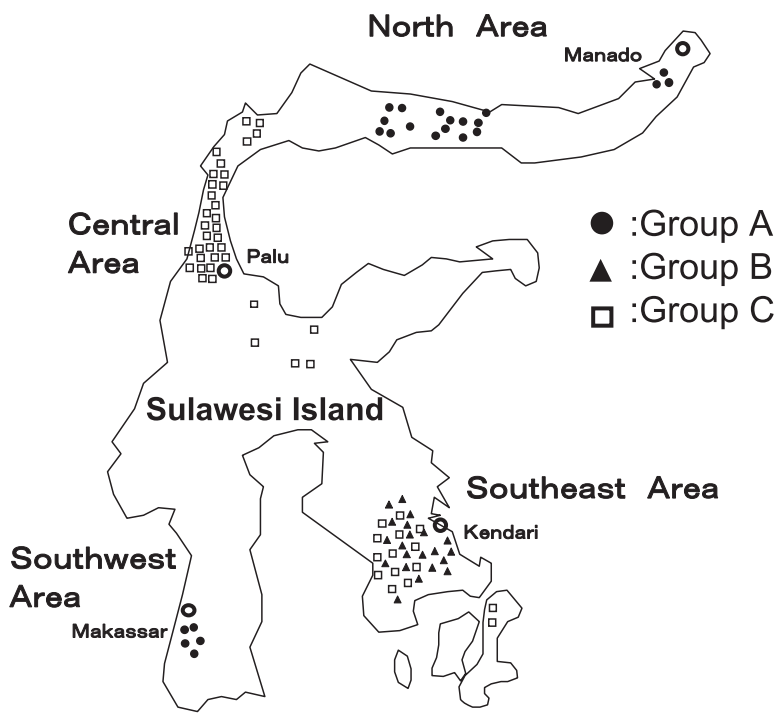

Fig. 3. Geographical distribution of mtDNA haplotypes of $S$. celebensis on Sulawesi Island. Numbers of samples showing different groups are indicated by symbols ( $\bullet$ : group A, $\mathbf{\Lambda}$ : group B, and $\square$ : group C) in Table 2 and Fig. 2.

western Sulawesi, those in group B were found from southeastern Sulawesi, and those in group C were found from central and southeastern Sulawesi (Fig. 3).

\section{Discussion}

In order to explore the genetic origin of domestic pigs, we have investigated the diversity of $S$. scrofa mtDNA sequences isolated from wild boars in Japan, Korea, China and Vietnam. In this study, we analyzed the mtDNA variation of domestic pigs and wild boars from Indonesian Islands. The NJ tree constructed with our data from Indonesian islands revealed that mtDNA haplotypes found in most $S$. scrofa wild boars from Sumatra and Java Islands, S. verrucosus from Java Island, and S. celebensis from Sulawesi Islands were different from those in the clade encompassing East and Southeast Asian domestic pig and wild boars (Fig. 2). However, the mtDNA haplotypes from domestic pigs on Lombok and Timor Islands were closely related to or within clade comprising East and Southeast Asian domestic pigs and wild boars. These results suggest that major indigenous wild boars in Indonesia were genetically separated from the continental wild boars and domestic pigs, and they did not contribute to Asian S. scrofa domestication events.

Seven mtDNA haplotypes (2006E1, 2006E4, 2006E10,
2007E21, 2007E26, 2007E31, and 2009I3) found in wild boars from Java, Sumatra, Sumbawa, Flores, and New Guinea Islands were related to two Vietnamese mtDNA haplotypes (viet12 and viet31). Although the haplotypes were not identical, the close genetic relationship between mtDNA haplotypes from wild boars between Vietnam and Indonesia found in this study is valuable. Based on archeological and genetic evidence, Larson et al. (2007) reported that domestic pigs bearing Vietnamese mtDNA haplotypes were certainly introduced to several islands east of the Wallace Line, including Lombok, Sumbawa, Flores, Timor and New Guinea Islands, and the so-called wild boars isolated from these islands are most likely feral descendants of domestic pigs introduced by early human immigrants. Based on the mtDNA phylogenies of wild boars from Vanuatu of Micronesia, Lum et al. (2006) reported that wild boars with Vietnamese haplotypes had dispersed during the human colonization of Remote Oceania with the Lapita cultural complex. The human-mediated dispersal routes of domestic pigs on several islands of Micronesia and Polynesia are closely associated with the diffusion of Lapita culture in the Pacific region (Larson et al. 2007). Thus, the close genetic relationship among Vietnam, Java and Sumatra Islands, and the five islands east of the Wallace Line observed in this study may also be associated with the early human dispersals or cultural diffusions as proposed by the other studies (Larson et al. 2005, 2007, 2010; Lum et al. 2006).

Two mtDNA haplotypes (2006W6 and 2006W11) found in $S$. verrucosus were not distinct from those from $S$. scrofa, although only two samples from $S$. verrucosus were examined in this study. Two species, $S$. scrofa and S. verrucosus, live in close proximity in a small area on Java Island and have some morphological resemblance. It was recently reported that crossbreeding between $S$. verrucosus and $S$. scrofa occurred on Java Island (Semiadi and Nugraha 2009). To clearly distinguish between $S$. verrucosus and $S$. scrofa, further genetic and morphological investigations would be required.

Larson et al. (2005) reported that two mtDNA clades were found on Sulawesi Island; one clade was associated with a northern population, and the other was associated with a southern population. The existence of two clades of $S$. celebensis on the Sulawesi Island led Larson et al. (2005) to speculate that there were two independent invasions of wild boar onto the Sulawesi Islands. In this study, the mtDNA haplotypes of $S$. celebensis were divided into three mtDNA groups A, B, and C (Fig. 2). 
Two mtDNA haplotypes, 2009SS1 and 2009SS4, belonging to the northern $S$. celebensis group A were detected in Makasar, located in the southwest (Fig. 3). In addition to group A, the mtDNA haplotypes of $S$. celebensis group $\mathrm{C}$ were widely dispersed in the central and southeastern areas of Sulawesi Island, while those of $S$. celebensis group B were only found in the southeastern area. The mtDNA haplotype analysis of $S$. celebensis revealed that $S$. celebensis populations are genetically composed of at least three mtDNA groups, and the geographical distribution is characteristic on Sulawesi Island. In this study, an S. scrofa sample with the same mtDNA haplotype (2009K19) as an $S$. celebensis sample was isolated from New Guinea. The ancestor of this mtDNA haplotype might have also been introduced to New Guinea from Sulawesi by ancient peoples. Similarly, Larson et al. (2007) provided evidence for an early human-mediated translocation of $S$. celebensis to Flores and Timor Islands. Taken together, these observations indicate that human-mediated introgression of wild boars or domestic pigs onto neighboring islands was an important factor in establishing the current geographical distribution of Sus populations (Gongora et al. 2004).

The phylogenetic study of mtDNA haplotypes of $S$. scrofa and other related species isolated from Indonesian islands revealed that mtDNA sequences of the $S$. scrofa populations from the Indonesian islands are extremely diverse. Molecular analyses of the origin and dispersal routes of domestic $S$. scrofa in and throughout Indonesia provide helpful information for understanding the activities and skills of ancient people, such as the domestication of pigs from wild boar and the subsequent introduction of livestock to neighboring islands. It is likely that the distribution throughout Pacific islands of current indigenous wild boars that are descendants of feral pigs is closely associated with dispersal of the Lapita cultural complex into Oceania (Lum et al. 2006; Larson et al. 2007). Future genetic analysis of indigenous wild boars from each Indonesian Island may provide detailed information about human-mediated introgression or movement of domestic pigs.

Acknowledgment: This study was supported in part by a Grant-in-Aid (No. 18405034) from the Ministry of Education, Culture, Sports, Science and Technology, Japan.

\section{References}

Chen, K., Baxter, T., Muir, W. M., Groenen, M. A. and Schook, L. B. 2007. Genetic resources, genome mapping and evolutionary genomics of the pig (Sus scrofa). International Journal of Biological Sciences 3: 153-165.

Felsenstein, J. 1985. Confidence limits on phylogenies: an approach using the bootstrap. Evolution 39: 783-791.

Giuffra, E., Kijas, J. M., Amarger, V., Carlborg, O., Jeon, J. T. and Andersson, L. 2000. The origin of the domestic pig: Independent domestication and subsequent introgression. Genetics 154: 17851791.

Gongora, J., Fleming, P., Spencer, P. B. S., Mason, R., Garkavenko, O., Meyer, J-N., Droegemueller, C., Lee, J. H. and Moran, C. 2004. Phylogenetic relationships of Australian and New Zealand feral pigs assessed by mitochondrial control region sequence and nuclear GPIP genotype. Molecular Phylogenetics and Evolution 33: 339-348.

Grubb, P. 2005. Artiodactyla. In (D. E. Wilson and D. M. Reeder, eds.) Mammal Species of the World: A Taxonomic and Geographic Reference, 3rd ed., pp. 637-722. John Hopkins University Press, Baltimore, U.S.A.

Hongo, H., Ishiguro, N., Watanobe, T., Shigehara, N., Anezaki, T., Long, V. T., Binh, D. V., Tien, N. T. and Nam, N. H. 2002. Variation in mitochondrial DNA of Vietnamese pigs: relationships with Asian domestic pigs and Ryukyu wild boars. Zoological Science 19: 1329-1335.

Ishiguro, N. and Nishimura, M. 2005. Genetic profile and serosurvey for virus infections of Japanese wild boars in Shikoku Island. The Journal of Veterinary Medical Science 67: 563-568.

Ishiguro, N., Sasaki, M., Iwasa, M., Shigehara, N., Hongo, H., Anezaki, T., Long, V. T., Hao, P. X., Trach, H. X., Nam, N. H. and Thanh, V. N. 2008a. Morphological and genetic analysis of Vietnamese Sus scrofa bones for evidence of pig domestication. Animal Science Journal 79: 655-664.

Ishiguro, N., Sasaki, M., Iwasa, M., Shigehara, N., Hongo, H., Anezaki, T., Long, V. T., Lan, D. T. B. and Long, P. T. 2008b. mtDNA variation in Vietnamese pigs, with particular emphasis on the genetic relationship between wild boars from Vietnam and the Ryukyu Islands. Mammal Study 33: 51-58.

Larson, G., Cucchi, T., Fujita, M., Matisoo-Smith, E., Robins, J., Anderson, A., Rolett, B., Spriggs, M., Dolman, G., Kim, T. H. Thuy, N. T., Randi, E., Doherty, M., Due, R. A., Bollt, R., Djubiantono, T., Griffin, B., Intoh, M., Keane, E., Kirch, P., Li, K. T., Morwood, M., Pedriña, L. M., Piper, P. J., Rabett, R. J., Shooter, P., Van den Bergh, G., West, E., Wickler, S., Yuan, J., Cooper, A. and Dobney, K. 2007. Phylogeny and ancient DNA of Sus provides insights into neolithic expansion in Island Southeast Asia and Oceania. Proceedings of the National Academy of Sciences of the United States of America 104: 4834-4839.

Larson, G., Dobney, K., Albarella, U., Fang, M., Matisoo-Smith, E., Robins, J., Lowden, S., Finlayson, H., Brand, T., Willerslev, E. Rowley-Conwy, P., Andersson, L. and Cooper, A. 2005. Worldwide phylogeography of wild boar reveals multiple centers of pig domestication. Science 307: 1618-1621.

Larson, G., Liu, R., Zhao, X., Zho, X., Yuan, J., Fuller, D., Barton, L., Dobney, K., Fan, Q., Gu, Z., Liu, X., Luo, Y., Lv, P., Andersson, L. and Li, N. 2010. Patterns of east Asian pig domestication, migration, and turnover revealed by modern and ancient DNA. Proceedings of the National Academy of Sciences of the United States of America 107: 7686-7691.

Lum, J. K., McIntyre, J. K., Greger, D. L., Huffman, K. W. and Vilar, M. G. 2006. Recent Southeast Asian domestication and Lapita 
dispersal of sacred male pseudohermaphroditic "tuskers" and hairless pigs of Vanuatu. Proceedings of the National Academy of Sciences of the United States of America 103: 17190-17195.

Okumura, N., Kurosawa, Y., Kobayashi, E., Watanobe, T., Ishiguro, N., Yasue, H. and Mitsuhashi, T. 2001. Genetic relationship amongst the major non-coding regions of mitochondrial DNAs in wild boars and several breeds of domesticated pigs. Animal Genetics 32: 139-147.

Saitou, N. and Nei, M. 1987. The neighbor-joining method: a new method for reconstructing phylogenetic trees. Molecular Biology and Evolution 4: 406-425.

Semiadi, G. and Nugraha, R. T. P. 2009. Some notes on biological aspects of captive javan warty pig (Sus verrucosus). Biodiversitas 10: $124-128$.

Tamura, K., Dudley, J., Nei, M. and Kumar, S. 2007. MEGA4: Molecular evolutionary genetics analysis (MEGA) software version 4.0.
Molecular Biology and Evolution 24: 1596-1599.

Thompson, J. D., Higgins, D. G. and Gibson, T. J. 1994. CLUSTAL $\mathrm{W}$ : Improving the sensitivity of progressive multiple sequence alignment through sequence weighting position-specific gap penalties and weight matrix choice. Nucleic Acids Research 22: 4673-4680.

Watanabe, T., Hayashi, Y., Ogasawara, N. and Tomita, T. 1985. Polymorphism of mitochondrial DNA in pigs based on restriction endonuclease cleavage patterns. Biochemical Genetics 23: 105113.

Watanobe, T., Ishiguro, N. and Nakano, M. 2003. Phylogeography and population structure of the Japanese wild boar Sus scrofa leucomystax: mitochondrial DNA variation. Zoological Science 20: $1477-1489$.

Received 25 December 2010. Accepted 17 August 2011 